\title{
Beyond malignancy: the role of carbohydrate antigen 125 in heart failure
}

\author{
Chung-Lieh Hung ${ }^{1,2,3,4,5}$, Ta-Chuan Hung ${ }^{1,3,5}$, Yau-Hui Lai ${ }^{1,3,5}$, Chi-Sheng Lu', Yih-Jer Wu ${ }^{1,3}$ and Hung-I Yeh ${ }^{1,3^{*}}$
}

\begin{abstract}
Carbohydrate antigen 125 (CA-125), traditionally a tumor marker for screening, diagnosis, and monitoring in ovarian malignancy, had recently been shown increasing evidence and more extensively recognized/explored as a novel surrogate of heart failure (HF). The exact mechanisms underlying the pathophysiologic link between elevated serum CA-125 concentration and HF may be multi-factorial, with both mechanical and inflammatory process including numerous potential cytokines involved. Accumulating data had consistently indicated its diagnostic and prognostic role in HF patients in various clinical settings, however, there is limited clinical information regarding the incremental value or head-to-head comparison of such marker to other well-established HF markers. In this brief review, we aimed to discuss the biosynthesis, and potential insights of underlying pathophysiologies associated with CA-125 secretion in the scenarios of cardiac structural/functional alterations and HF, and further explored its current usage and roles in several recent reports.
\end{abstract}

\section{Brief introduction}

Carbohydrate antigen 125 (CA-125), also known as MUC16, is a glycoprotein belonging to the mucin (MUC) family [1]. Humans CA-125, encoded by MUC16 gene, contains about 22,000 amino acids and is heavily glycosylated at the extracellular region (Figure 1), which can be released from the cell surface by undergoing proteolytic cleavage and hence released into body fluid, including blood, pleural effusion, and ascites. CA-125 was first detected in ovarian cancer cell line. Subsequent studies showed that it is normally expressed on the surface of cells derived from coelomic epithelium, including pleura, epicardium, fallopian tubes, endometrium, and endocervix. With rich oligosaccharide chains, the physiological role of CA-125 is considered to protect the epithelial luminal surfaces from physical stress through hydration or lubrication process $[2,3]$.

\section{The role of CA-125 in malignancy and non-cardiac} pathophysiology

Clinically CA-125 has long been used as a marker for ovarian cancer [4-6]. In patients with ovarian cancer,

\footnotetext{
* Correspondence: hiyeh@ms1.mmh.org.tw

'Departments of Internal Medicine and Medical Research, Mackay Memorial Hospital, Taipei, Taiwan

${ }^{3}$ Department of Medicine, Mackay Medical College, New Taipei City, Taiwan Full list of author information is available at the end of the article
}

accumulated evidence showed that serum levels of CA-125 is helpful in the monitoring of the cancer and further aid in risk stratification and prognosis after treatment $[7,8]$. However, a rise of serum CA-125 level is not limited to ovarian cancer alone. Other gynaecological malignancies or non-gynaecological malignancies including lung cancer, mediastinal teratoma, and even non-Hodgkin's lymphoma, have been reported to be associated with a high serum CA-125 level [9-11]. Apart from malignancies, elevation of CA-125 can been seen in situations involving several physiologic or pathologic conditions including early pregnancy, menstruation, peritoneal trauma, and ascites of any cause $[12,13]$. Hepatic cirrhosis as a cause of CA-125 elevation, for example, had been mentioned to be the most frequent diagnosis in male patients ${ }^{7}$. Another example is that elevation of CA-125 may happen in subjects with pleural effusion [14]. Based on these findings, clinical interpretation of elevated CA-125 should be exercised with caution, in part may be due to its restriction in specificity of diagnosing a single clinical disease entity or scenario.

\section{The link between CA-125, left-sided cardiac structural/ functional alterations and heart failure}

Since CA-125 is expressed in epicardium, it is not surprising that cardiac disorders may be associated with elevated CA-125 levels in the blood. Nagele and associates firstly reported the findings of clinical or hemodynamical

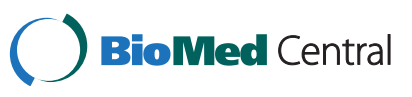




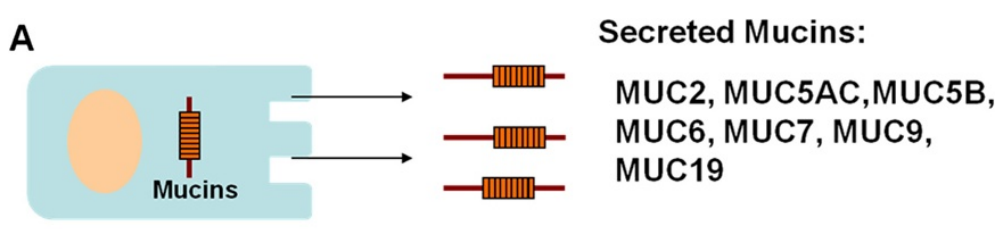

Membrane associated Mucins:

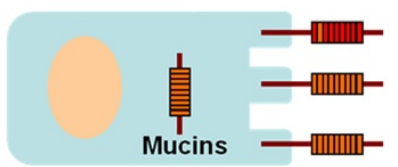

MUC1, MUC3, MUC4, MUC12, MUC13, MUC15, MUC16, MUC17, MUC20

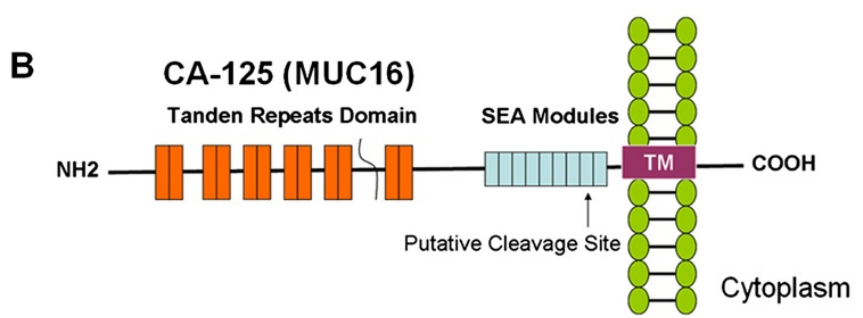

Figure 1 The Mucin family glycoproteins. (A) There are two classes of mucins generated in the cells: secreted mucins and membrane associated mucins. (B) Diagram of the structure of CA-125. CA-125 is encoded by the MUC16 gene which is located on human chromosome 19. CA-125 contains a tandem repeat domain that has repeating sequences high in serine, threonine and proline and is highly O-glycosylated. The C-terminal domain of CA-125 contains multiple extracellular SEA (sea urchin sperm protein, enterokinase, and agrin) modules, a transmembrane (TM) domain, and a cytoplasmic tail. CA-125 is also thought to be putatively cleaved at a site in the SEA modules.

relevance of several tumor markers, with a special focus on CA-125, in patients with chronic heart failure before and after heart transplantation [15]. Duman et al. ever described a weak association between CA-125 level and right side pulmonary artery pressure, though in that case no association was found between CA-125 level and leftside cardiac hemodynamic (mostly diastolic) parameters [16]. Similar finding was reported by Kouris et al. [17]. What may merit noteworthy is that, Duman et al. also showed that CA-125 was associated with left atrial volume as a supplement to the severity indices of diastolic dysfunction along with BNP levels [16]. In our recent work, we demonstrated that in subjects with HF but preserved LVEF (HFpEF), CA-125 was actually associated with LA remodeling in terms of higher volume rather than other parameters, which may highlight that clinical significance or findings that diastolic impairment or left sided hemodynamic disturbances linked to CA-125 may actually come from left atrial remodeling [18]. On the contrary, D'Aloia et al. demonstrated an association between CA-125 level and both right heart hemodynamics and left ventricular diastolic function [19]. Compared to the former study, data reported by D'Aloia et al. had larger total patient population across a wide range of HF severity in terms of NYHA functional class (Fc) (Duman et al.: 49, Kouris et al.: 77 versus D'Aloia et al.: 286) leading to larger amount of Fc IV population (Duman et al.: 16, Kouris et al.: 16 versus D'Aloia et al.: 83 ) in D'Aloia's series, and potentially higher number of subjects (28/49 versus
152/286) having CA-125 above normal range (35 U/ml). Differences in total patient numbers, disease severity and distributions may in part explain the potential differences in such correlations. In the same study, D'Aloia also reported that subsequently lower CA-125 at follow up was related to clinical improvement by NYHA class as a positive response to therapy. Again, another study by Vizzardi et al. with larger patient number enrolled and wider range of clinical HF subjects $(n=200$, NYHA Fc II-IV) reported that both systolic and diastolic indices, cardiac diameter, and diastolic functional parameters correlated with CA125 level [20]. In one study, CA-125 distinguished subjects with acute decompensated HF [21], and further showed prognostic significance (Table 1). The predictive value for all-cause mortality up to 6-months after index HF hospitalization had also been demonstrated by the same study group [22]. On the other hand, there also seems to be a moderate correlation between CA-125 and brain natriuretic peptide (BNP) level, the most commonly used biomarker reflecting degree of excessive ventricular wall stress, hemodynamics or ventricular filling abnormalities in left-sided HF [23,24]. Interestingly, though both markers had been reported to rise in acute heart failure, combination of them in clinical use may further improve risk stratification at follow up [23,25]. Nevertheless, the elevation of CA-125 in the context of left-sided HF had been proposed to be associated with disease severity in terms of NYHA functional class, $[20,22]$ echocardiographic parameters, and clinical conditions such as effusions or edema [13,23]. 
Table 1 Comparisons of previous CA-125 related heart failure research and reports from previous studies

\begin{tabular}{|c|c|c|c|c|c|}
\hline & Subjects number & HF presentations & Clinical status & Left side hemodynamics & Outcomes available \\
\hline Kouris et al. [17] & $N=77$ & AHF & V & $\mathrm{V}$ & $?$ \\
\hline Nunez et al. [21] & $N=1,111$ & AHF & V & $?$ & V \\
\hline Nägele et al. [15] & $N=71$ & $\mathrm{CHF}$ & V & $?$ & V \\
\hline D'Aloia et al. [19] & $N=286$ & $\mathrm{CHF}$ & V & - & V \\
\hline Vizzardi et al. [20] & $N=200$ & $\mathrm{CHF}$ & V & V & $?$ \\
\hline Duman et al. [16] & $N=49$ & $\mathrm{CHF}$ & V & v & $?$ \\
\hline Chen [24] & $N=285$ & $\mathrm{CHF}$ & V & V & $?$ \\
\hline Yilmaz et al. [28] & $N=150$ & All comers & $?$ & V & V \\
\hline Hung et al. [18] & $N=35$ & HFpEF & $x$ & V & V \\
\hline
\end{tabular}

V, Positive Finding, -, Negative Finding, ?, Not Reported.

\section{The clinical associations between CA-125 and right-sided heart failure}

Significant elevation of CA125 level in a patient having atrial septal defect (ASD) with right ventricular dilatation was ever reported by Mathew et al. [26]. The association between CA125 and right ventricular parameters, either structural or functional, in subjects presented as chronic obstructive pulmonary disease (COPD) had also been described [27,28]. In Yilmaz's work, 40 patients with another age- and gender-matched control group with detailed transthoracic echocardiography were examined [28]. They observed that patients with higher systolic pulmonary artery pressure as well as lower tricuspid annular plane systolic excursion or worse tricuspid annulus systolic velocity $\left(S^{\prime}\right)$ all had significantly higher CA-125 levels than did those without. In another retrospective work (totally 150 patients enrolled) by Yilmaz et all reported that elevated CA-125 level was associated with worse left ventricular ejection fraction and positively correlated with systolic pulmonary artery pressure [29]. In particular, patients with right ventricular dilatation had significantly higher CA-125 levels compared to those without. They also concluded that patients with high CA-125 level encountered more frequent hospitalization, atrial fibrillation and mortality at future follow up. This work actually pointed out the potential link between bi-ventricular failure and elevated CA-125 level was not confined to only right or left ventricle alone.

\section{Possible mechanisms linking elevated CA-125 to clinical heart failure}

Interpretation of elevated CA-125 levels in HF should consider the triggering factors as well as the production sites. These issues have been investigated and no simple answer was found. So far, production of CA-125 in subjects with HF had been hypothesized to happen with socalled "stressed" mesothelial cells, in response to both hemodynamic and inflammation stimuli [30]. It had been proposed that fluid overload accompanied by high venous pressure due to heart failure may increase the congestion and hydrostatic pressure in mesothelium, [31] which may actually provoke the release of several inflammatory markers such as interleukin-6 (IL-6), interleukin-10 (IL-10), and tumor necrosis factors. In this regard, serosal irritation due to inflammation process, mechanical stress, or fluid congestion all might stimulate mesothelial cells to initiate CA-125 synthesis [32,33]. The synthetic capacity of mesothelium of CA-125 had been demonstrated by Zeillemaker et al., who investigated the secretion pattern of CA-125 using mesothelial cell monolayer as an in vitro model [34] by utilizing several inflammatory cytokines including interleukin-1 (IL-1), tumor necrosis factor- $\alpha$ and lipopolysaccharides as stimuli. Apical secretion of CA-125 was shown in 6 hours, with the most effective stimuli observed to be IL-1. Congestion as a hallmark of clinical HF manifestation may involve pulmonary congestion/edema, pleural effusion and ascites, which are believed to be interrelated with systemic inflammation activation as a vicious cycle [35]. The formation of congestion itself as a consequence of HF had made the splanchnic bed with an abundance of mesothelial cells exposed to high-venous pressure and ascitis (Figure 2). Furthermore, the combination of both pathological process may thus further contribute to neurohumoral-axis activation facilitating CA-125 production [36]. Additionally, the possible translocation of bacteria or endotoxin formation during the exacerbation of $\mathrm{HF}$, a condition most likely to happen in subjects presenting with right heart failure as well as gastrointestinal functional impairment in the context of bowel congestion with HF, may also play a key role in the "hyper-response" of CA-125 from mesothelium [37].

On the other hand, the hypothetical link between pericardial stimuli and elevation of CA-125 in subjects with HF had also been observed. Seo et al. [38] ever reported a $59 \%$ positive staining in the pericardial mesothelial cells, while Soma et al. reported a negative finding [39]. More or 


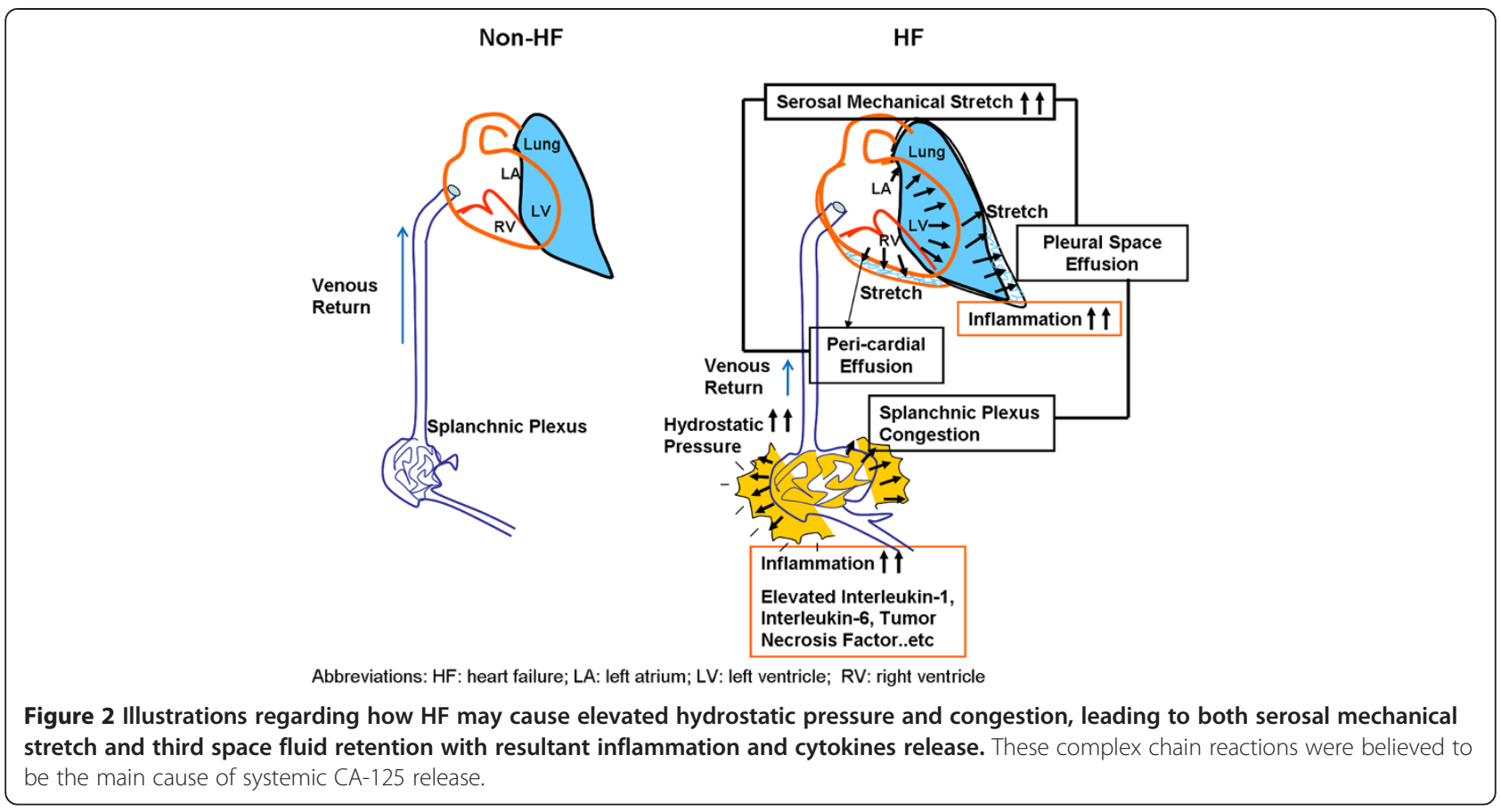

less, accumulating evidence had indicated the mesothelium (pericardial, pleura or peritoneum) as a potential primary source of CA-125 in HF or other non-malignant clinical scenarios $[40,41]$, while data regarding the severity or extent of underlying stimuli, inducing media or modalities, and whether such elevation in HF was also secondarily influenced by effusions per se or other associated cytokines still remained a debate [41]. Perhaps, all these possibilities exist, but just contribute differentially according to the severity and etiologies of HF. To clarify these issues, experiments studying animal models of HF mimicking different presentations of human HF encountered clinically may provide the solution. This approach will determine the major production sites of CA-125 as well as the major stimuli in various stages of $\mathrm{HF}$.

\section{Potential clinical application of CA-125 in HF}

The range of value and potential clinical implication of CA-125 regarding its predictive value in monitoring HF beyond and the correlates with other well-established HF markers (e.g. BNP or NT-ProBNP) remained largely unknown. In general, serum CA-125 level seemed to be 7-fold higher (HF: $105.2 \pm 139$, range 4.6 to $1169.5 \mathrm{U} / \mathrm{ml}$ vs Control: $14.9 \pm 22 \mathrm{U} / \mathrm{ml}$, respectively) in subjects with acute HF, 2.5 times in chronic HF (HF: $68 \pm 83$, range 3 to $537 \mathrm{U} / \mathrm{ml}$ ) [23] and nearly 1.5 times higher in female HFpEF (HFpEF: $17.6 \pm 10.2$, range 4.94 to $104.3 \mathrm{U} / \mathrm{ml}$ ) [18], the value actually had wide range across a heterogeneous spectrum in specific subgroups of HF patients $[12,26,29,32,39]$. Previous work on healthy volunteers showed that serum CA-125 level differences may exist between healthy pre- (mean level: $12.6 \mathrm{U} / \mathrm{ml}$ ) and postmenopausal women $(10.5 \mathrm{U} / \mathrm{ml})$ though without statistical significance, with significant lower value was observed in healthy men when compared to pre-menopausal women (9.2 vs $12.6 \mathrm{U} / \mathrm{ml}, \mathrm{p}=0.007$ ) [42]. Serum CA-125 had shown significant correlation with BNP level, elevated LV end-diastolic filling pressure and larger LA volume in systolic HF [16], so far there is a paucity of data on the incremental value of CA 125 when added on BNP. Though comparable long-term (14 \pm 2 months) predictive value for CA 125 when compared to NT-ProBNP in stable, chronic systolic HF had recently been tested in a feasibility study with much lower cost (about 10 times less expensive for CA 125 vs NT-ProBNP, roughly U.S. $\$ 1.07$ vs $\$ 10.74$ ) [43]. The lack of change in serum CA 125 concentration rather than NT-ProBNP seemed to confer higher risk of death in systolic HF during a 3-month therapeutic interval. [44] In addition to the potential clinical application in patients with systolic heart failure, CA125 may help to clarify the uncertain management of patients with HFpEF [45]. The incremental value of CA 125 superimposed on NT-ProBNP in female HFpEF was proved in our work recently [18]. Interestingly, all these studies showed statistically significant association between NT-ProBNP and CA-125 level. However, all these reports were of smaller sample size and used a diversity of clinical outcomes as end-points. Thereafter, a large scale study with specific HF patients population and well-defined clinical outcomes may be necessary for a head-to-head 
comparison between CA-125 and other commonly used HF biomarkers.

\section{Conclusion}

With better understanding of the underlying biological mechanisms and pathophysiological processes of heart failure in the recent era, biomarker as a surrogate in disease screening, diagnosis, or as a guide to effects of therapy or outcomes had broadened the utilization of these tools by physicians in clinical settings. The incremental clinical value by using multi-biomarker panel looking into potentially diverse pathways or biological signaling involved in a clinical disease entity are evolving. CA-125, the glycoprotein primarily used for ovarian cancer screening or therapeutic monitoring, is gaining more and more attention as another role in heart failure. Insights into the understanding of its role and mechanisms involved in heart failure had made it different from other biomarkers for the same purpose, though questions and issues regarding the real determinants for such glycoprotein release, short- and long-term monitoring for treatment, and the potential costs as a routine marker for heart failure may worth further investigation.

\section{Competing interests}

The authors declare that they have no competing interests.

\section{Authors' contributions}

CLH drafted the manuscript. TCH and YHL had made substantial contributions to conceptual framework of this review. CSL had participated the graphing of CA125 molecular structure and figure edition. YJW involved in the drafting of the manuscript. HIY have given final approval of the version to be published. All authors read and approved the final manuscript.

\section{Author details}

${ }^{1}$ Departments of Internal Medicine and Medical Research, Mackay Memorial Hospital, Taipei, Taiwan. ${ }^{2}$ The Institute of Health Policy and Management, College of Public Health, National Taiwan University, Taipei, Taiwan. ${ }^{3}$ Department of Medicine, Mackay Medical College, New Taipei City, Taiwan. ${ }^{4}$ Department of Health Industry Management, Kainan University, Taoyuan, Taiwan. ${ }^{5}$ Mackay Junior College of Medicine, Nursing and Management, New Taipei City, Taiwan.

Received: 11 July 2013 Accepted: 19 August 2013 Published: 30 August 2013

\section{References}

1. Yin BWT: Molecular cloning of the CA125 ovarian cancer antigen. identification as a new mucin, muc16. J Biol Chem 2001, 276(29):27371-27375.

2. Bafna S, Kaur S, Batra SK: Membrane-bound mucins: the mechanistic basis for alterations in the growth and survival of cancer cells. Oncogene 2010, 29:2893-2904.

3. Gaetje R, Winnekendonk DW, Ahr A, Kaufmann M: Ovarian cancer antigen CA-125 influences adhesion of human and mammalian cell lines in vitro. Clin Exp Obstet Gynecol 2002, 29(1):34-36.

4. Bischof P: What do we know about the origin of CA-125? Eur J Obstet Gynecol Reprod Biol 1993, 49:93-98.

5. Bast RC Jr, Xu FJ, Yu YH, Barnhill S, Zhang Z, Mills GB: CA-125: the past and the future. Int I Biol Markers $1998,13: 179-187$.

6. Whitehouse C, Solomon E: Current status of the molecular characterization of the ovarian cancer antigen CA125 and implications for its use in clinical screening. Gynecol Oncol 2003, 88:S152-S157.

7. Halila H, Stenman UH, Seppala M: Ovarian cancer antigen CA-125 levels in pelvic inflammatory disease and pregnancy. Cancer 1986, 57:1327-1329.
8. Barbieri RL, Niloff JM, Bast RC Jr, Scaetzl E, Kistner RW, Knapp RC: Elevated serum concentrations of CA-125 in patients with advanced endometriosis. Fertil Steril 1986, 45:630-634.

9. Molina R, Filella X, Jo J, et al: CA-125 in biological fluids. Int J Biol Markers 1998, 13:224-230.

10. Lindgren J, Kuusela P, Hellström PE, Pettersson T, Klockars M: The ovarian cancer associated antigen CA-125 in patients with pleural effusions. Eur J Cancer Clin Oncol 1988, 24:737-739.

11. Yilmaz MB, Nikolaou M, Cohen SA: Tumour biomarkers in heart failure: is there a role for CA-125? Eur J Heart Fail 2011, 13:579-583.

12. Epiney M, Bertossa C, Weil A, Campana A, Bischof P: CA125 production by the peritoneum: in-vitro and in-vivo studies. Hum Reprod 2000, 15:1261-1265.

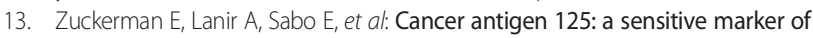
ascites in patients with liver cirrhosis. Am J Gastroenterol 1999, 94:1613-1618.

14. Mezger J, Wilmanns W, Lamerz R: Elevated serum CA-125 levels in patients with benign ascitic or pleural effusions. Tumour Biol 1988, 9:47-52.

15. Nägele H, Bahlo M, Klapdor R, Schaeperkoetter D, Rödiger W: CA-125 and its relation to cardiac function. Am Heart J 1999, 137:1044-1049.

16. Duman D, Palit F, Simsek E, Bilgehan K: Serum carbohydrate antigen 125 levels in advanced heart failure: relation to B-type natriuretic peptide and left atrial volume. Eur J Heart Fail 2008, 10:556-559.

17. Kouris NT, Zacharos ID, Kontogianni DD, Goranitou GS, Sifaki MD, Grassos HE, Kalkandi EM, Babalis DK: The significance of CA125 levels in patients with chronic congestive heart failure. Correlation with clinical and echocardiographic parameters. Eur J Heart Fail 2005, 7:199-203.

18. Hung CL, Hung TC, Liu CC, Wu YJ, Kuo JY, Hou CJ, Yeh HI: Relation of carbohydrate antigen-125 to left atrial remodeling and its prognostic usefulness in patients with heart failure and preserved left ventricular ejection fraction in women. Am J Cardio/ 2012, 110:993-1000.

19. D'Aloia A, Faggiano P, Aurigemma G, Bontempi L, Ruggeri G, Metra M, Nodari S, Dei CL: Serum levels of carbohydrate antigen 125 in patients with chronic heart failure: relation to clinical severity, hemodynamic and doppler echocardiographic abnormalities, and short-term prognosis. J Am Coll Cardiol 2003, 41:1805-1811.

20. Vizzardi E, Nodari S, D’Aloia A, Chiari E, Faggiano P, Metra M, Dei CL: CA-125 tumoral marker plasma levels relate to systolic and diastolic ventricular function and to the clinical status of patients with chronic heart failure. Echocardiography 2008, 25:955-960.

21. Nunez J, Sanchis J, Bodi V, et al: Improvement in risk stratification with the combination of the tumour marker antigen carbohydrate 125 and brain natriuretic peptide in patients with acute heart failure. Eur Heart J 2010, 31:1752-1763.

22. Núñez J, Núñez E, Consuegra L, Sanchis J, Bodí V, Martínez-Brotons A, Bertomeu-González V, Robles R, Bosch MJ, Fácila L, Darmofal H, Llàcer A: Carbohydrate antigen 125: an emerging prognostic risk factor in acute heart failure? Heart 2007, 93:716-721

23. Faggiano P, D'Aloia A, Brentana L, Bignotti T, Fiorina C, Vizzardi E, Dei CL: Serum levels of different tumour markers in patients with chronic heart failure. Eur J Heart Fail 2005, 7:57-61.

24. Chen YX, Wang XQ, Fang CF, Wang JF, Tang LJ: Value of BNP and tumour marker CA125 in patients with heart failure. Acta Cardiol 2008, 63:501-506.

25. Núñez J, Núñez E, Sanchis J, Bodí V, Fonarow GC, Miñana G, Palau P, Bertomeu-González V, Carratalá A, Mainar L, Chorro FJ, Llàcer A: Antigen carbohydrate 125 and brain natriuretic peptide serial measurements for risk stratification following an episode of acute heart failure. Int J Cardiol 2012, 159:21-28.

26. Mathew $B$, Bhatia $V$, Mahy IR, Ahmed I, Francis L: Elevation of the tumor marker CA125 in right heart failure. South Med J 2004, 97(10):1013-1014.

27. Uz O, Kardesoglu E, Tas D, Acar G, Isilak Z, Yiginer O, Aparci M, Cingozbay BY, Cebeci BS: CA-125 level is associated with right ventricular echocardiographic parameters in patients with COPD. South Med J 2011, 104:624-628.

28. Yilmaz MB, Zorlu A, Dogan OT, Karahan O, Tandogan I, Akkurt I: Role of CA-125 in identification of right ventricular failure in chronic obstructive pulmonary disease. Clin Cardiol 2011, 34:244-248.

29. Yilmaz MB, Zorlu A, Tandogan I: Plasma CA-125 level is related to both sides of the heart: a retrospective analysis. Int J Cardiol 2011, 149:80-82.

30. Zeimet AG, Offner FA, Marth C, Heim K, Feichtinger H, Daxenbichler G, Dapunt O: Modulation of CA-125 release by inflammatory cytokines in human peritoneal mesothelial and ovarian cancer cells. Anticancer Res 1997, 17:3129-3131. 
31. Kosar F, Aksoy Y, Ozguntekin G, Ozerol I, Varol E: Relationship between cytokines and tumour markers in patients with chronic heart failure. Eur J Heart Fail 2006, 8(3):270-274.

32. Turgut O, Tandogan I, Yilmaz MB, Gul I, Gurlek A: CA125 levels among patients with advanced heart failure: an emerging independent predictor for survival. Int J Cardiol 2010, 145:71.

33. Huang F, Chen J, Liu Y, Zhang K, Wang J, Huang H: New mechanism of elevated CA125 in heart failure: the mechanical stress and inflammatory stimuli initiate CA125 synthesis. Med Hypotheses 2012, 79:381-383.

34. Zeillemaker AM, Verbrugh HA: Hoynck van Papendrecht AA, Leguit P. CA-125 secretion by peritoneal mesothelial cells. J Clin Pathol 1994, 47:263-265.

35. Minana G, Nunez J, Sanchis J, Bodi V, Nunez E, Llacer A: CA125 and immunoinflammatory activity in acute heart failure. Int I Cardiol 2010, 145:547-548.

36. Gheorghiade M, Follath F, Ponikowski P, Barsuk JH, Blair JE, Cleland JG, Dickstein K, Drazner MH, Fonarow GC, Jaarsma T, Jondeau G, Sendon JL, Mebazaa A, Metra M, Nieminen M, Pang PS, Seferovic P, Stevenson LW, van Veldhuisen DJ, Zannad F, Anker SD, Rhodes A, McMurray JJ, Filippatos G: European society of cardiology; European society of intensive care medicine. assessing and grading congestion in acute heart failure: a scientific statement from the acute heart failure committee of the heart failure association of the European society of cardiology and endorsed by the European society of intensive care medicine. Eur J Heart Fail 2010, 12:423-433.

37. Krack A, Sharma R, Figulla HR, Anker SD: The importance of the gastrointestinal system in the pathogenesis of heart failure. Eur Heart J 2005, 26:2368-2374.

38. Seo T, Ikeda $Y$, Onaka $H$, et al: Usefulness of serum CA125 measurement for monitoring pericardial effusion. Jpn Circ J 1993, 57:489-494.

39. Soma $L$, Allen $M$, Tobin $L$, et al: CA-125 concentrations in patients awaiting cardiac transplantation. Clin Chem 2002, 48:2289-2290.

40. Colombo PC, Ganda A, Lin J, Onat D, Harxhi A, lyasere JE: Inflammatory activation: cardiac, renal, and cardio-renal interactions in patients with the cardiorenal syndrome. Heart Fail Rev 2012, 17:177-190.

41. Topatan B, Basaran A: CA-125 and heart failure: déjà vu or "still to be seen". Int J Cardiol 2010, 145:626-629.

42. Zustovich F, Buja A, Da Prà M, Farina G, Zovato S, Buttarello M, Perissinotto E, Cartei G: CA-125 behaviour by gender and potential prognostic role in early stage lung cancer. Cancer Therapy 2007, 5:347-350.

43. Ordu S, Ozhan H, Alemdar R, Aydin M, Caglar O, Yuksel H, Kandis H: Carbohydrate Antigen-125 and N-terminal pro-brain natriuretic peptide levels: compared in heart-failure prognostication. Tex Heart Inst J 2012, 39:30-35.

44. Folga A, Filipiak KJ, Mamcarz A, Obrebska-Tabaczka E, Opolski G: Simultaneous predictive value of NT-proBNP and CA-125 in patients newly diagnosed with advanced heart failure: preliminary results. Arch Med Sci 2012, 8:637-643.

45. Chung-Lieh H, Charles Jia-Yin H, Gwo-Chi H, Jen-Yuan K, Chia-Yu H, Cheng-Ho T, Hung-I Y, Bulwer BE, Ya-Ching $\mathrm{H}$ : Myths and facts about heart failure with preserved ejection fraction: risk factors, longevity, potential pharmacological and exercise interventions. Int J Gerontol 2013, 7:1-7.

doi:10.1186/2050-7771-1-25

Cite this article as: Hung et al: Beyond malignancy: the role of carbohydrate antigen 125 in heart failure. Biomarker Research 2013 1:25.

\section{Submit your next manuscript to BioMed Central and take full advantage of:}

- Convenient online submission

- Thorough peer review

- No space constraints or color figure charges

- Immediate publication on acceptance

- Inclusion in PubMed, CAS, Scopus and Google Scholar

- Research which is freely available for redistribution 